\title{
Estudo da incorporação de fármaco em dispositivo de liberação obtido da fibroína de seda
}

\author{
B. T. TOMODA ${ }^{1}$, M. M. BEPPU ${ }^{1}$, M. A. de MORAES ${ }^{2}$ \\ ${ }^{1}$ Universidade Estadual de Campinas, Faculdade de Engenharia Química \\ ${ }^{2}$ Universidade Federal de São Paulo, Departamento de Ciências Exatas e da Terra \\ E-mail para contato: mamoraes@unifesp.br
}

\begin{abstract}
RESUMO - A fibroína de seda é um polímero natural presente nos casulos dos bichos-da-seda da espécie Bombyx mori e apresenta um grande potencial para utilização como biomaterial, devido à sua resistência mecânica, biocompatibilidade e biodegradabilidade. Uma das maneiras de utilização da fibroína de seda como biomaterial é na forma de membrana densa, que pode ser explorada para usos na cicatrização de ferimentos e queimaduras. A possibilidade de incorporação de outros materiais na membrana, tais como fármacos e nanopartículas, aumenta a gama de aplicações da membrana de fibroína de seda, possibilitando o preparo de um dispositivo de liberação controlada. O objetivo desse trabalho é o estudo de métodos de incorporação de um fármaco modelo (diclofenaco de sódio) em membranas densas de fibroína de seda, para usos futuros como dispositivo de liberação controlada, especialmente na área de curativos de alto desempenho. Como métodos de incorporação foram estudados: 1) incorporação da solução de fármaco diretamente na solução de fibroína, antes do preparo da membrana; 2) incorporação por adsorção da solução de diclofenaco na membrana de fibroína. Foram analisadas as características visuais e de solubilidade das membranas obtidas pelos diferentes métodos, bem como feitas caracterizações por FTIR e MEV, que permitiram a escolha do melhor método de incorporação

do

fármaco.
\end{abstract}

\section{INTRODUÇÃO}

A pele, órgão de revestimento externo do corpo, tem como funções a proteção, regulação térmica e sensorial do organismo. As lesões na pele podem prejudicar o sistema de defesa, sendo necessário um tratamento adequado para a recuperação do mesmo (Veiga, 2012). Assim sendo, o preparo de curativos para a administração de fármacos, como o diclofenaco de sódio, a partir de membranas formadas por polímeros naturais, é um meio de combate aos danos da pele e às inflamações que podem surgir devido à lesão.

Recentemente, membranas formadas a partir de polímeros naturais têm sido estudadas, pois tais polímeros são obtidos de fontes renováveis e são biodegradáveis. Para determinar a eficiência de um biopolímero, suas propriedades físicas, químicas e mecânicas são analisadas, podendo-se observar que a grande maioria dos polímeros naturais ou sintéticos possui boas propriedades para utilização na área biomédica. Dentre os polímeros naturais, a fibroína de seda apresenta-se como uma fonte promissora para a produção de biomateriais (Moraes, 2010). 
A fibroína de seda é uma proteína presente nos casulos de bichos-da-seda da espécie Bombyx mori constituída majoritariamente por alanina, glicina e serina (Altman et al, 2003). A fibroína possui três tipos principais de conformações da estrutura secundária: hélice- $\alpha$, enovelamento aleatório e folha- $\beta$. As conformações do tipo hélice- $\alpha$ e enovelamento aleatório também são chamadas de Seda I, enquanto que a conformação do tipo folha- $\beta$ é denominada de Seda II. A estrutura folha- $\beta$ é a forma mais estável da fibroína (Moraes, 2010).

Neste projeto, busca-se preparar membranas de fibroína de seda contendo um fármaco modelo, de maneira a preparar um dispositivo de liberação controlada de fármaco, visando aplicações na área de curativos de alto desempenho. Dentro deste contexto, o estudo do método de incorporação do fármaco é fundamental, uma vez que poderá afetar diretamente as propriedades do material resultante.

O fármaco modelo escolhido foi o diclofenaco de sódio, um anti-inflamatório e analgésico comercializado mundialmente. Pode ser apresentado em comprimidos, em solução e outras formas, dependendo da necessidade de utilização no tratamento.

\section{OBJETIVO}

Estudar métodos de incorporação de um fármaco modelo em membranas de fibroína de seda, a fim de obter um dispositivo de fibroína de seda para liberação controlada de fármaco.

\section{MATERIAIS E MÉTODOS}

\subsection{PREPARO DA SOLUÇÃO DE FIBROÍNA DE SEDA}

Foram utilizados casulos de bichos-da-seda da espécie Bombyx mori, fornecidos pela fiação de seda Bratac (Bastos/SP). Para remoção da sericina foi utilizada solução aquosa de carbonato de sódio $\left(\mathrm{Na}_{2} \mathrm{CO}_{3}\right) 1 \mathrm{~g} / \mathrm{L}$, a $85^{\circ} \mathrm{C}$, durante $1 \mathrm{~h} 30$, com trocas de solução a cada 30 minutos. Os fios foram então secos a temperatura ambiente e moídos em moinho de facas com rotor tipo ciclone (TE-651/2, Tecnal) até fração passante na peneira de mesh $n^{\circ} 10$ (partícula com $2 \mathrm{~mm}$ de diâmetro), a fim de facilitar a dissolução.

A solução de fibroína de seda foi preparada em uma concentração de $10 \%$, utilizando solução ternária de cloreto de cálcio, etanol e água $\left(\mathrm{CaCl}_{2}: \mathrm{CH}_{3} \mathrm{CH}_{2} \mathrm{OH}: \mathrm{H}_{2} \mathrm{O}\right.$ 1:2:8 molar) a $85^{\circ} \mathrm{C}$. Esta solução foi dialisada em água destilada por 3 dias, a $10^{\circ} \mathrm{C}$, para a remoção do cálcio presente na solução e obtenção de solução aquosa de fibroína.

\subsection{PREPARO DAS MEMBRANAS}

As membranas foram preparadas pelo método de casting, no qual a solução de fibroína dialisada foi vertida em placas de Petri de poliestireno e o solvente foi evaporado à temperatura ambiente em capela.

Para a incorporação do diclofenaco de sódio nas membranas de fibroína de seda, utilizouse uma concentração fixa de $10 \mathrm{mg} / \mathrm{mL}$ de diclofenaco.

Foram estudados diferentes métodos de incorporação do diclofenaco de sódio na membrana de fibroína de seda: 1) incorporação da solução aquosa de diclofenaco de sódio 
diretamente na solução aquosa de fibroína de seda; 2) incorporação do diclofenaco por adsorção na membrana de fibroína por aproximadamente 48 horas.

No processo de incorporação do diclofenaco de sódio por adsorção na membrana de fibroína, o diclofenaco de sódio foi dissolvido em água e em etanol 70\%. No entanto, para a adsorção em água, foi necessário um tratamento prévio da membrana em etanol. $\mathrm{O}$ tratamento consistiu em colocar as membranas de fibroína de seda em etanol $70 \%$ por 60 minutos para torná-las menos solúveis em água e então foi realizada a incorporação do diclofenaco dissolvido em água na membrana de fibroína.

\subsection{CARACTERIZAÇÃO DAS MEMBRANAS}

As amostras foram caracterizadas por espectroscopia de infravermelho por transformada de Fourier (FT-IR) em um Nicolet 6700 da Thermo Scientific no modo ATR (membranas de fibroína pura e com diclofenaco) e no modo transmitância (método $\mathrm{KBr}$ - diclofenaco de sódio). A análise no modo ATR ocorreu na faixa de $4000-675 \mathrm{~cm}^{-1}$ e 128 scans e no modo transmitância ocorreu na faixa de $4000-400 \mathrm{~cm}^{-1}$ e 32 scans.

A morfologia das membranas foi analisada em Microscópio Eletrônico de Varredura com Espectroscopia por Dispersão de Energia de Raios X (LEO/ Leo 440i). Para isto, as membranas foram fraturadas em nitrogênio líquido e recobertas com ouro antes da análise,sendo analisadas na superfície e na fratura em $10 \mathrm{kV}$ e $50 \mathrm{pA}$.

\section{RESULTADOS}

A Figura 1 mostras os espectros de FTIR das membranas de fibroína de seda pura e com diclofenaco de sódio adicionado por incorporação na solução de fibroína, assim como o diclofenaco de sódio utilizado na incorporação.

Figura 1 - Espectros de infravermelho das membranas de fibroína com e sem diclofenaco e do diclofenaco de sódio em pó.

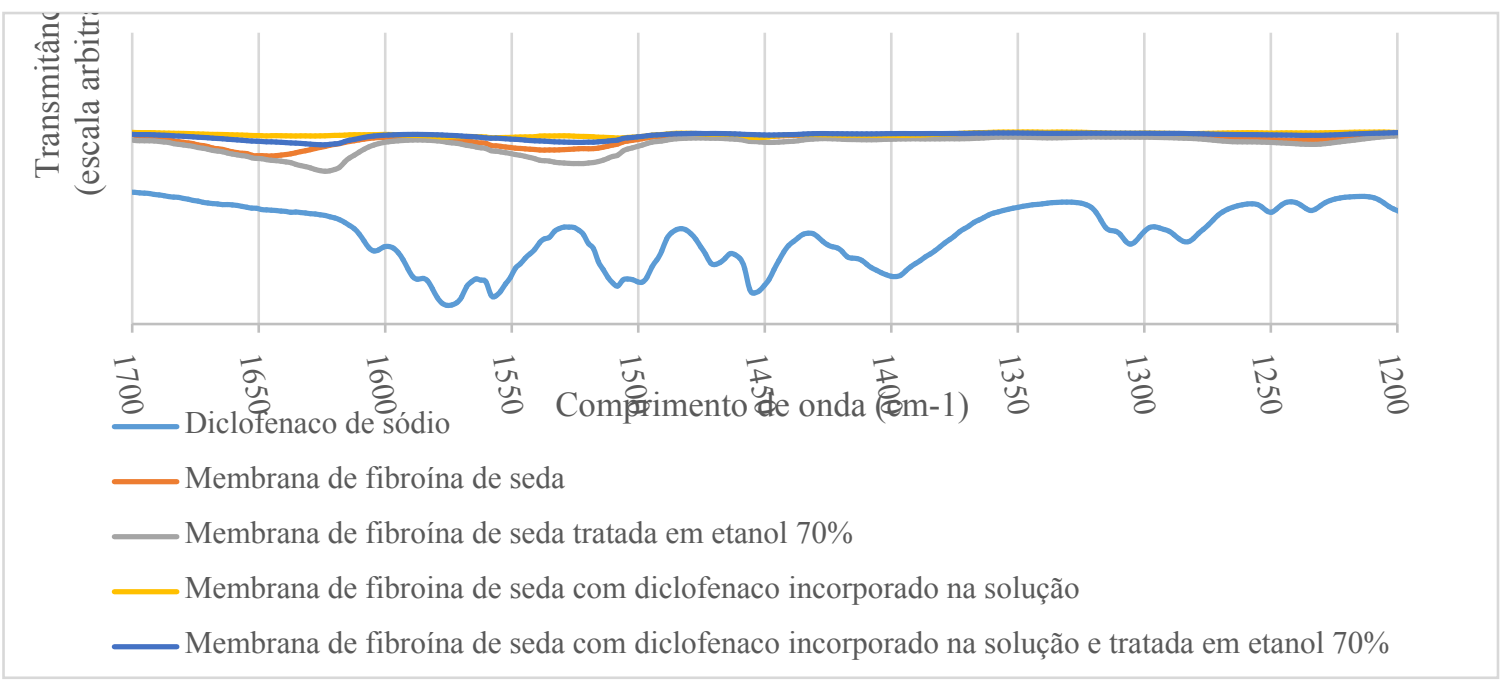


Conforme pode ser observado na Figura 1, os espectros de infravermelho da membrana de fibroína de seda pura e de fibroína de seda tratada em etanol $70 \%$ diferem. A alteração no espectro demonstra que o tratamento em etanol $70 \%$ induz a transição da fibroína de Seda I para Seda II, mais estável e insolúvel em água, conforme já observado na literatura (Nogueira, 2009)

Ainda na Figura 1, pode-se notar que os espectros das membranas com diclofenaco de sódio incorporado na solução de fibroína com e sem tratamento com etanol $70 \%$ são semelhantes e indicam que a fibroína está em sua conformação mais estável, Seda II. Assim sendo, a incorporação do diclofenaco de sódio induz naturalmente uma transição conformacional da fibroína de seda para Seda II, eliminando a necessidade do tratamento com etanol 70\%. Para comprovar e testar a maior estabilidade da membrana com diclofenaco de sódio incorporado na solução de fibroína sem tratamento em etanol $70 \%$, a mesma foi imersa em água por $48 \mathrm{~h}$ e não apresentou indícios de dissolução. Este fato é diferente da membrana de fibroína pura, que dissolve completamente quando imersa em água, havendo então a necessidade de tratamento em etanol $70 \%$ para torná-la mais estável em água (Nogueira, 2009).

Figura 2: Espectros de infravermelho da membrana com diclofenaco de sódio dissolvido em água (A) e em etanol 70\% (B) e incorporado por adsorção.
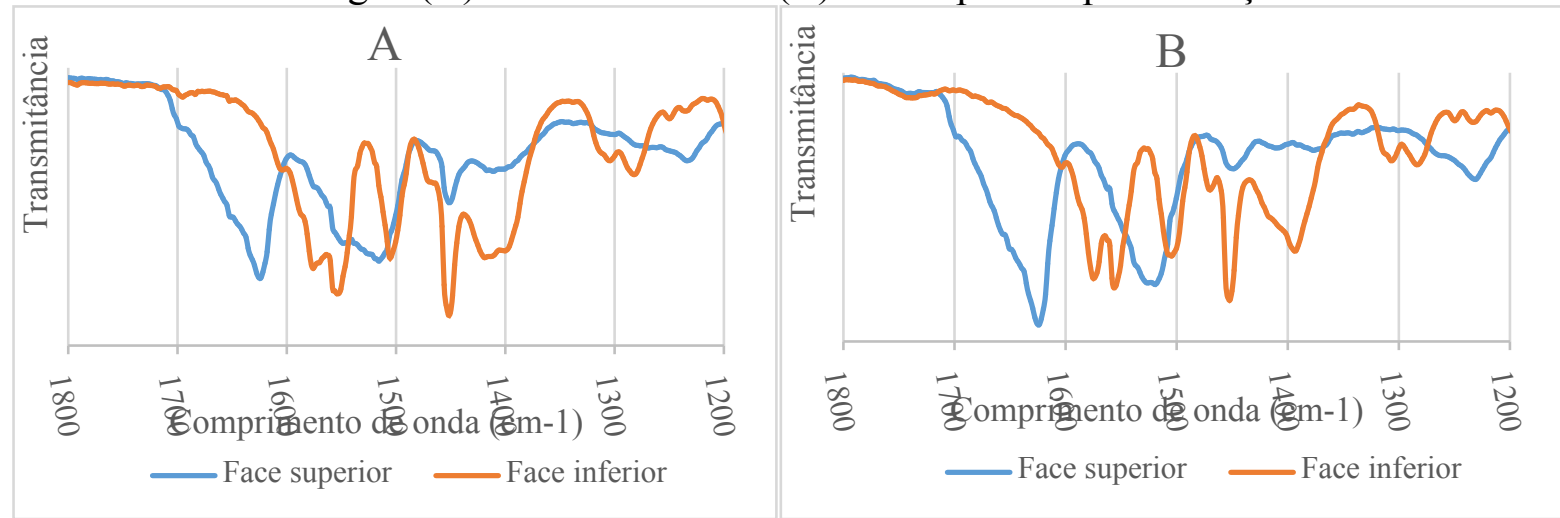

Os espectros de infravermelho obtidos das membranas preparadas pelo método de incorporação do fármaco por adsorção, Figura 2, indicam resultados diferentes para cada face da membrana, o que está relacionado com o método de incorporação do fármaco. Na face superior, os dados dos espectros indicam a conformação da fibroína em Seda II, mais estável. Já na face inferior, tem-se a predominância de picos relacionados ao diclofenaco de sódio, indicando que o mesmo está concentrado na superfície. Para confirmar esta hipótese e analisar a morfologia das membranas com a incorporação do fármaco foram obtidas imagens de MEV.

Figura 4 - Micrografias de superfície (1) das membranas com mapeamento de sódio (pontos vermelhos) e de fratura (2). A: membrana com diclofenaco de sódio dissolvido em água e incorporado por adsorção; B: membrana com diclofenaco de sódio dissolvido em etanol $70 \%$ e incorporado por adsorção; C e D: membrana com diclofenaco de sódio dissolvido em água e incorporado na solução de fibroína.

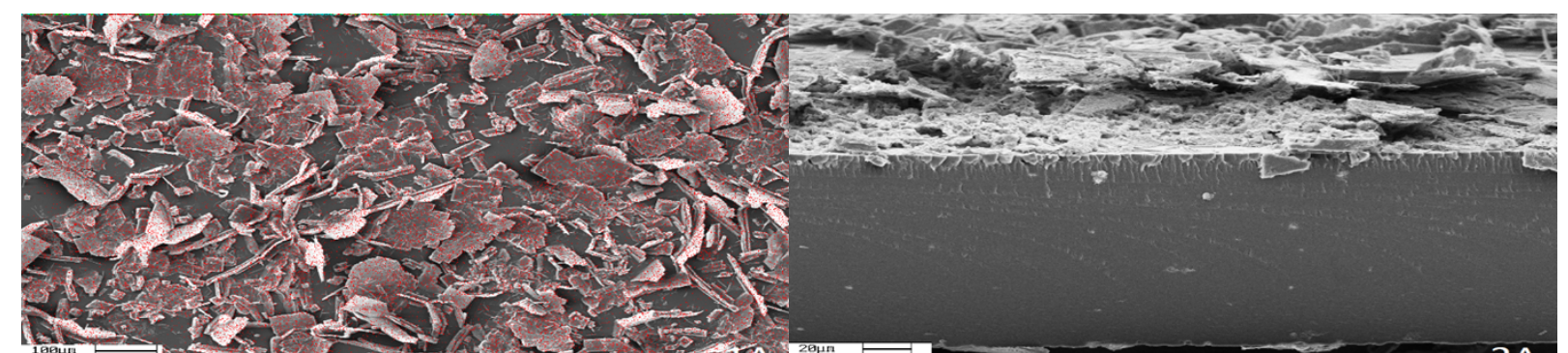




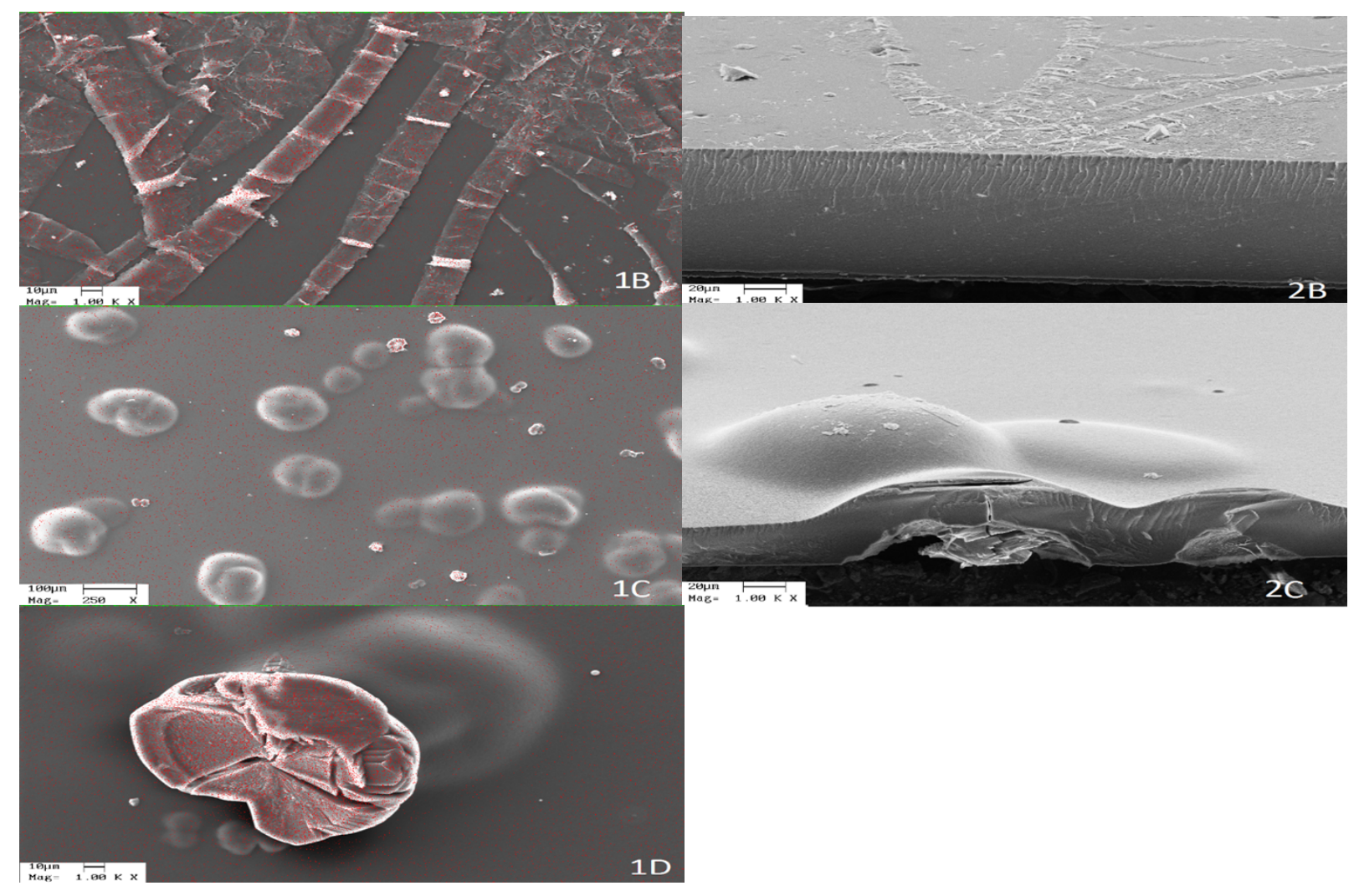

Nas Figuras 4 A e B, nota-se que o diclofenaco de sódio encontra-se apenas na superfície, mostrando que o processo de adsorção nesses casos não atingiu o resultado esperado. Esperava-se que o diclofenaco estivesse presente em toda a membrana de fibroína de seda, sendo possível obter um maior controle da liberação do fármaco devido a difusão do mesmo no interior da membrana. Assim sendo, as imagens obtidas por MEV estão de acordo com o resultado de FTIR e confirmam a suposição da incorporação do diclofenaco de sódio por adsorção concentrar o fármaco nas superfícies.

$\mathrm{Na}$ Figura $4 \mathrm{C}$, nota-se que o diclofenaco de sódio não está concentrado na superfície, mas sim no interior da membrana de fibroína de seda, que apresentou a formação de partículas esféricas. Com o auxílio do mapeamento por espectroscopia de energia dispersiva do sódio (pontos vermelhos da figura 4), nota-se a baixa presença do diclofenaco na superfície da membrana, com distribuição uniforme. Entretanto, em alguns pontos foi observada a eclosão das partículas esféricas, sendo possível observar grande concentração do diclofenaco. Este processo foi espontâneo neste método de incorporação e possivelmente resultante de uma separação de fases, com formação de partículas de fibroína contendo diclofenaco aprisionado em seu interior. Este resultado é muito promissor e poderá resultar em uma liberação mais controlada do fármaco estudado. 

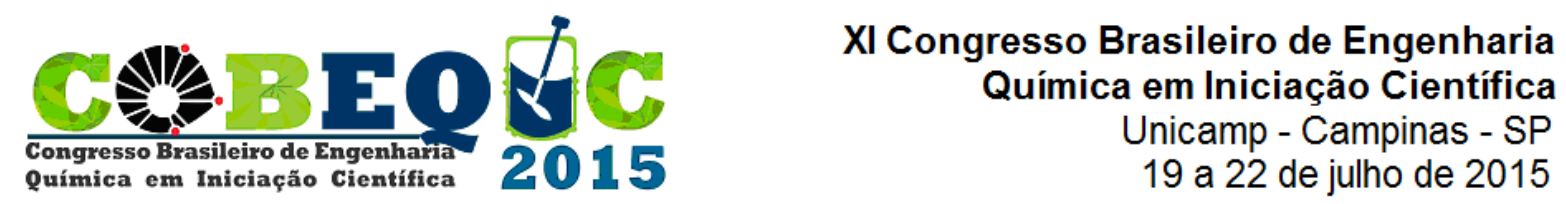

\section{Conclusão}

A incorporação do diclofenaco de sódio diretamente na solução de fibroína de seda apresentou uma interação relevante ao alterar a conformação da fibroína de Seda I para Seda II, sem a necessidade de um tratamento posterior para torná-la estável.

Comparando os diferentes métodos realizados para a incorporação do diclofenaco de sódio em membranas de fibroína de seda, o método da incorporação da solução de diclofenaco na solução de fibroína mostrou ser o mais eficiente. Este método possibilitou a transição da fibroína para sua forma mais estável, dispensando o uso de pós-tratamento, além de ter formado espontaneamente partículas de fibroína com fármaco aprisionado, o que poderá resultar em condições otimizadas de liberação do fármaco.

Assim sendo, membranas densas de fibroína de seda apresentam potencial para serem utilizadas como dispositivo de liberação controlada. Ensaios de liberação do fármaco estão sendo realizados como desdobramento deste trabalho.

\section{BIBLIOGRAFIA}

ALTMAN, G.H., et al. Silk-based biomaterials. Biomaterials, v. 24, n. 3, p. 401-416, 2003.

MORAES, M.A., Obtenção e caracterização de blendas e compósitos poliméricos de fibroína de seda e alginato de sódio. Tese (Mestrado em Engenharia Química), Faculdade de Engenharia Química, Universidade Estadual de Campinas, Campinas. 2010.

NOGUEIRA, G.M., Hidrogéis e filmes de fibroína de seda para fabricação ou recobrimento de biomateriais. Tese (Doutorado em Engenharia Química), Faculdade de Engenharia Química, Universidade Estadual de Campinas, Campinas, 2009.

VEIGA, I.G., Produção e caracterização de membranas de quitosana associada com outros biopolímeros para liberação controlada de anti-inflamatórios. Tese (Doutorado em Engenharia Química), Faculdade Engenharia Química, Universidade Estadual de Campinas, Campinas, 2012. 